\title{
Androgen Receptor Antagonist SHR3680
}

National Cancer Institute

\section{Source}

National Cancer Institute. Androgen Receptor Antagonist SHR3680. NCI Thesaurus.

Code C126335.

An orally bioavailable androgen receptor (AR) antagonist with potential antineoplastic activity. Upon administration, SHR3680 competitively binds to AR in target tissues, which both prevents androgen-induced receptor activation and facilitates the formation of inactive complexes that cannot be translocated to the nucleus. This prevents binding to and transcription of AR-responsive genes, inhibits the expression of genes that regulate prostate cancer cell proliferation, and may lead to an inhibition of cell growth of ARexpressing tumor cells. ARs are overexpressed in prostate cancer and play a key role in prostate cancer cell proliferation. 